\title{
Myocardial metastases from neuroendocrine tumors: incidence and relevance
}

\author{
Dik J. Kwekkeboom
}

Received: 24 January 2014/ Accepted: 10 April 2014/Published online: 26 June 2014

(C) Springer Science+Business Media New York 2014

Well-differentiated neuroendocrine tumors of pancreatic or gut origin (formerly termed pancreatic NETs and carcinoids) frequently metastasize to lymph nodes and liver. Myocardial metastases are far less frequent and estimated at $1-4 \%$ of cases [1-4]. In their article on the detection with $\quad\left[{ }^{68} \mathrm{Ga}\right.$-DOTA $\left.{ }^{0}, \mathrm{Tyr}^{3}\right]$ octreotide $\quad\left({ }^{68} \mathrm{Ga}\right.$-DOTATOC $)$ $\mathrm{PET} / \mathrm{CT}$ of heart metastases from ileal neuroendocrine tumors, elsewhere in this volume, Calissendorff et al. [5] report an incidence of $4.3 \%$ (4/92 patients). All 4 patients presented with metastatic disease, and 3 of them had bone involvement, which is usually associated with widespread disease and constitutes a negative prognostic factor.

The percentage of cardiac involvement is in line with two other reports [2,3], but significantly higher than that was found in two other studies [1,4]. This may be because of differences in the populations that were studied (i.e., any neuroendocrine tumor versus ileal neuroendocrine tumors only), but also because of an improved tumor detection rate or sensitivity of the diagnostic tests that are applied. In this respect, PET/CT with ${ }^{68}$ Ga-labeled somatostatin analogs performs better than the commercially available Octreoscan, which uses $\left[{ }^{111}\right.$ In-DTPA $\left.{ }^{0}\right]$ octreotide and a "classical" gamma-camera. As a consequence, also the detection of "rare" metastatic tumor sites increases.

The question is what therapeutic consequence the finding of myocardial metastases has: fatal cardiac complications in patients with myocardial involvement are rarely reported in the literature, and, therefore, a surgical approach in such patients, as discussed by Calissendorff et al., may be questioned. As stated previously, myocardial metastases are usually detected in patients with high tumor burden. Instead of a focus on the surgical approach of cardiac metastases, it can be argued as well that the extent of widespread disease and its progression should primarily guide the decision and choice of treatment, rather than whether or not myocardial metastases are present.

I fully agree with Calissendorff et al., however, that more reports are needed to clarify the clinical significance of finding cardiac metastases in this patient group.

D. J. Kwekkeboom ( $₫)$

Department of Nuclear Medicine, Erasmus Medical Center,

Rotterdam, The Netherlands

e-mail: d.j.kwekkeboom@erasmusmc.nl 


\section{References}

1. H. Jann, T. Wertenbruch, U. Pape, C. Ozcelik, T. Denecke, S. Mehl, B. Wiedenmann, M. Pavel, A matter of the heart: myocardial metastases in neuroendocrine tumors. Horm. Metab. Res. 42, 967-976 (2010)

2. P.A. Pellikka, A.J. Tajik, B.K. Khandheria, J.B. Seward, J.A. Callahan, H.C. Pitot, L.K. Kvols, Carcinoid heart disease. Clinical and echocardiographic spectrum in 74 patients. Circulation 87, 1188-1196 (1993)
3. U.H. Pandya, P.A. Pellikka, M. Enriquez-Sarano, W.D. Edwards, H.V. Schaff, H.M. Connolly, Metastatic carcinoid tumor to the heart: echocardiographic-pathologic study of 11 patients. J. Am. Coll. Cardiol. 40, 1328-1332 (2002)

4. C. Carreras, H.R. Kulkarni, R.P. Baum, Rare metastases detected by (68)Ga-somatostatin receptor PET/CT in patients with neuroendocrine tumors. Recent Results Cancer Res. 94, 379-384 (2013)

5. J. Calissendorff, A. Sundin, H. Falhammer, 68 Ga-DOTA-TOCPET/CT detects heart metastases from ileal neuroendocrine tumors. Endocrine (2013). doi:10.1007/s12020-013-0108-7 